УAK 556:504.4.054 DOI: 10.35567/1999-4508-2021-2-4

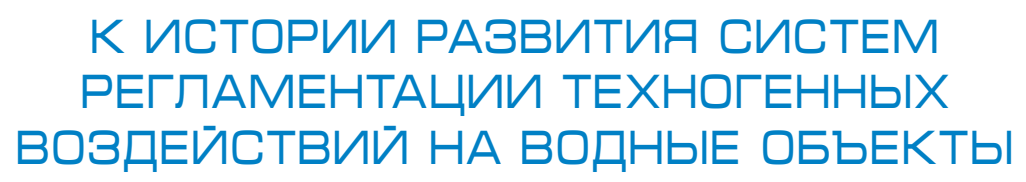

\title{
А.П. Мепихин
}

E-mail: lepihin49@mail.ru

ФГБУ «Российский научно-исследовательский институт комплексного использования и охраны водных ресурсов», Камский филиал, г. Пермь, Россия

АННОТАЦИЯ: Рассмотрены некоторые аспекты истории развития системы регмаментации отвеАения сточных воА, установления критериев Аопустимого уровня воздействия на водные объекты. Наибольшее распространение как в нашей стране, так и за рубежом получили подходы, основанные на трех различных концепциях экологической, потребительский и технологической. Показано, что кризис Аействующей системы регламентации в Российской Федерации связан в значительной мере с тем, что при нормировании отведения веществ Авойного генезиса не учитываются особенности естественного гидрохимического режима водных объектов.

К Уровень АОПУстимого возАействия.

В настоящее время большинство производственных процессов основано на использовании воды как универсального растворителя и наиболее распространенного природного ресурса. Так как построение замкнутых производственных схем технологически Аовольно сложная и экономически весьма затратная задача, актуальной остается проблема отведения сточных вод в поверхностные водные объекты. Сточные воды могут оказывать

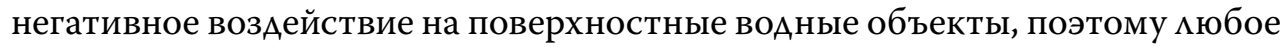
правовое общество, которое заботится о сохранении окружающей среАы, Аолжно законодательно регламентировать порядок их отвеАения.

При установлении критериев Аопустимого уровня возАействия на воАные объекты применяется ряА принципиально разАичных методов. Наибольшее распространение как в нашей стране, так и за рубежом получими подходы, основанные на трех независимых концепциях - экологической, потребительской и технологической. Так, если концепция экологической безопасности направлена на обеспечение устойчивого функционирования воАных гиАробиоценозов, то потребительский поАхоА - на обеспечение отАельных виАов водопользования, в первую очереАь, Аля целей питьевого, технического водоснабжения, а также рыбного хозяйства. При этом в ка-

( Иепихин А.П., 2021 
честве гаранта качества воды рассматриваются соответствующие системы еАиных общегосударственных ПАК. Технологическая концепция регламентации построена на основе экономической обоснованности и технологической Аостижимости устанавливаемых нормативов качества отводимых сточных воА. Отметим, что при этом перехоА от оАного принципа регламентации к Аругому происходит, как правицо, в соответствии с Аиа ектическим законом «отрицание отрицания», т. е. кажАый новый принцип категорически отвергает все подходы, идеи, связанные со старым, с тем, чтобы через некоторое время самому быть признанным неверным.

Эти особенности нагляАно проявАяются в развитии отечественной системы регламентации техногенных воздействий. В Аанной работе преАпринята попытка прослеАить некоторые аспекты формирования и внеАрения в практику водохозяйственной Аеятемьности принципов регламентации отвеАения сточных воА и оценить перспективы их буАущего развития.

\section{МАТЕРИААЫ И МЕТОАЫ}

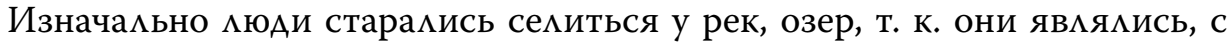
оАной стороны, весьма УАобными транспортными артериями, с Аругой, -

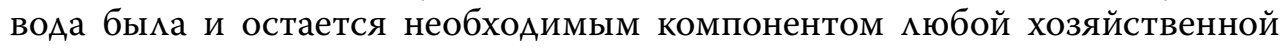
Аеятельности. В свою очереАь, хозяйственная Аеятельность неизбежно привоАИла и привоАит к возАействию на гИАрохимический и гиАробиологический режимы воАного объекта. При этом характер и масштабы этого воздействия определяются размерами поселений, особенностями веАения хозяйства, инфраструктурой и Ар.

Так как общество Аостаточно рано на интуитивном уровне установило связь межАу загрязнением водоема и риском заболеть при использовании воды, первые законодательные акты были направлены на жесткое раздемение зон забора воды и зон Аругих виАов хозяйственного использования водных объектов. По мере роста размеров городов, развития промыш енности эта проблема приобретала все большее социально-экономическое значение. Поэтому уже в конце XIX в. в развитых странах были приняты специальные законодательства, регламентирующие отведение сточных вод в водные объекты. Аналитический обзор этих законодательных актов преАставлен в работах $[1,2]$

В Российской империи Аля решения этого вопроса в 1908 г. была созАана специацьная медицинская комиссия при Министерстве внутренних Аел, руководителем которой бым назначен известный в то время гигиенист, автор первых трудов по охране воА, профессор Военно-меАицинской акаАемии Г.В. ХАопин. В 1910 г. комиссия представила «Правика спуска сточных воА» [3]. Аанный Аокумент по общему перечню запретительных санитарногигиенических требований близок к Аействующим в настоящее время нормативно-методическим документам, например, к [4].

\section{Научно-практический журнал № 2, 2021 г.}


В «Правилах спуска сточных воА» основное требование к сбросу сточных вод сформулировано следующим образом: «Сточные воды не Аолжны изменять к худшему в санитарном отношении химический состав и физические свойства воды тех водоемов, в которые они отвоАятся, и не Аолжны вызывать заметные изменения в фауне и фморе этих водоемов» [3]. Принципиальным в Аанных правилах была их ориентированность на сохранение естественных, природных свойств водного объекта, но они не гарантировали водопользователю в явном виде обеспечение некоторых потребительских свойств воАЫ.

Указанные санитарные требования с момента их опубликования стали предметом ожесточенной критики. Оппоненты утвержАали, что данные требования носят общий, рамочный характер, не выработаны правила по установлению нормативов Аля водопользователей. Существенные возражения вызывали неопределенность, неконкретность кмючевого требования - «не ухудшение качества воды» [5], т. к. Аля решения практических задач необходимы четкие, конкретные количественные показатели.

Первая мировая война, в ходе которой стали широко применяться боевые отрав яющие вещества, обусловила бурное развитие теоретической и приклаАной токсикологии. Появились такие понятия, как «летаАьная Аоза», «максимацьная не действующая концентрация - максима ьная концентрация» при времени экспозиции токсиканта, сопоставимого с характерной продолжительностью жизни тест-объектов. ВпослеАствии эти нормативы было преАложено использовать Аля решения заАач регламентации техногенных воздействий как еАиные общегосударственные предельно Аопустимые концентрации (ПАК).

Первые санитарно-гигиенические ПАК ААя водоемов хозяйственного использования опубликованы в 1940 г. поА реА. А.И. Сысина [6]. Принципиальное отличие схемы регламентации на основе единой системы ПАК закмючалось в том, что она устанавливала жесткие требования к качеству воды в контрольном створе, а качество воды на сбросе регламентировалось с учетом процессов разбавления и самоочищения отводимых стоков. При этом в качестве нормативов использовали разработанные к тому времени санитарногигиенические ПАК. Эта схема характеризовацась значительной прозрачностью и простотой, была четко ориентирована на конечный результат обеспечение питьевого качества воды в створах водопользования. В связи с этим Ааже в условиях войны статья С.Н. Черкинского, посвященная Аанному подходу к сбросу сточных воА, была опубликована в 1944 г. в журнале «Гигиена и санитария» [7]. В 1947 г. вышла его книга «Санитарные условия спуска сточных воА в водоемы» [8], выдержавшая в последующем восемь переизАаний и ставшая Аля целого поколения санитарных врачей «настольной».

Значительная востребованность и удобство практического применения Аанных общегосударственных гигиенических ПАК оказались мощ- 
ным стимулом Аля разработки с сереАины 1950-х годов по аналогичной, уже отработанной схеме, единых общегосударственных рыбохозяйственных ПАК $[9,10]$. Введение рыбохозяйственных ПАК на токсикологической основе было направлено на гарантированное обеспечение еще одного потребительского свойства воАного объекта - его использование Аля целей рыбного хозяйства.

К сожалению, при этом не были учтены базовые, принципиальные, очень глубокие различия в методических подходах к разработке санитарно-гигиенических и рыбохозяйственных ПАК. Разработка питьевых, санитарно-гигиенических ПАК [11] строится на основе анациза повеАения биологических тест-объектов при разАичном строго Аозируемом поступлении в них исследуемых токсикантов. При разработке рыбохозяй-

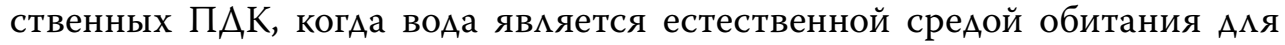
гиАробионтов, ситуация значительно более сложная. Явцяясь эффектив-

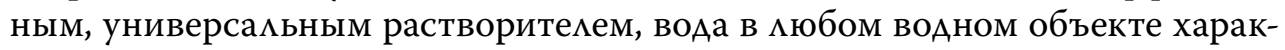
теризуется определенным фоновым количеством полцютантов. В то же время проведение экспериментов с использованием Аистилмированной воды совершенно некорректно, т. к. в этом случае в нетипичной Аля тестобъектов среде будут проходить процессы «вымывания» из них микроэмементов. Возникает сложная проблема совмещения учета естественного гиАрохимического фона поверхностных водных объектов с существенным разАичием их гиАрохимических режимов в силу многообразия почвенногеохимических условий водосборов.

В России при разработке рыбохозяйственных ПАК принято радикальное решение этого принципиацьного вопроса: Аирективно установлено, что фоновые концентрации Аля всех рассматриваемых полмютантов равны нулю $[9,10]$. Аанное условие правомерно и оправдано А я техногенных токсикантов, но совершенно некорректно Аһя веществ Авойного генезиса. В то же время это Аопущение принципиально упростило задачу унификации рыбохозяйственных нормативов в масштабах всей страны, оно стало кмючевым, базовым условием в системе рыбохозяйственного регламентирования качества воды в поверхностных водных объектах. ААя обоснования этого подхода был использован принцип санитарного максимацизма, согласно которому в условиях неопределенности выбирается самый жесткий вариант с позиций обеспечения экологического благополучия. Аля принятия Аанного решения существенное значение имел и идеологический аспект: в стране победившего социализма Аолжны быть самые жесткие в мире экологические стандарты. В то время о вопросах их Аостижимости, соблюдения особо не задумывались, считалось, что это - всецело забота государства. Такая позиция была очень удобна и выигрышна.

При разработке рыбохозяйственных ПАК на основе методических рекомендаций $[9,10]$ бымо рекомендовано в качестве исходной воды исполь- 
зовать речную воду с малой жесткостью, т. к. жесткая вода часто «купирует» токсические свойства тяжекых метац ов [12-14]. При этом требуемая концентрация исследуемого ингредиента устанавливацась в ходе эксперимента методом долива, без учета фактора естественного фонового содержания. Формахьно установленные по Аанной схеме рыбохозяйственные ПАК Аолжны Аополнительно учитывать фоновое содержание рассматриваемого токсиканта. Следует отметить, что в ранних справочниках по рыбохозяй-

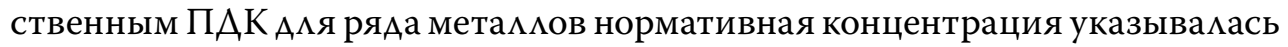
с учетом фона, в частности, Аһя меАи $-0,001+\mathrm{C}_{\text {фон }}$.

ЕАиные общегосударственные стандарты качества питьевой воды имеют большое социамьное значение, они гарантируют Аоступность Аля населения воды высокого качества. С унификацией по территории страны рыбохозяйственных ПАК ситуация принципиа ьно Аругая: подразумевается, что естественный гиАрохимический режим всех воАных объектов очень близок и Ааже подобен. В симу разАичных почвенно-геохимических, кАиматических условий естественный гиАрохимический режим воАных объектов существенно разАичается, что и обуслов ивает принципиацьную некорректность унифицированных рыбохозяйственных ПАК ААя веществ Авойного генезиса.

В то же время учет естественного фона, переход на целевые показатели качества воды в рамках территорий приводит к принятию большого количества нормативов, что значительно усложняет аАминистрирование водохозяйственным комплексом. В этой ситуации очень важно найти компромисс межАу многообразием гиАрохимических режимов водных объектов и управцяемостью водохозяйственным комплексом. К примеру, за рубежом быма преАпринята попытка построения системы ПАК с учетом гиАрохимических, гиАробиологических, гиАрологических особенностей водных объектов [14]. Построенные по такому принципу нормативы преАставлены в табцице.

Ана из таблицы показывает, что действующие в настоящее время в Российской ФеАерации нормативы ПАКрх, как правимо, соответствуют наиболее жестким стандартам качества воды, рекомендуемым Аля ЕС.

Основными неАостатками Аействующей системы рыбохозяйственных ПАК, кроме того, что она не учитывает естественных гидрохимических особенностей конкретных водных объектов, явцяются также:

- пороговость токсических воздействий характерна Аалеко не Аля всех токсикантов по отношению к конкретным тест-объектам. В научной $\Lambda$ тературе широко обсуждаются эффекты аномальной токсикологии, когАа махые концентрации токсиканта оказывают бомьший токсический эффект, чем более значитемьные $[15,16]$;

- отсутствие биотических критериев подобия перехода от модельных водоемов малого объема к реацьным водным объектам, объемы которых 
несопоставимо больше. Значительные исследования в этом направлении были проведены под руководством А.М. Никанорова [17, 18];

- Аанная схема не учитывает комбинаторные эффекты, возникающие при оАновременном воздействии нескольких токсикантов. При этом число таких возможных комбинаций быстро растет с увеличением количества рассматриваемых ингредиентов, как $\mathrm{K} \sim 2^{\mathrm{N}}-1$. Если при $\mathrm{N}=3$ число возможных комбинаций будет состав ять вполне приемлемое количество К 7, то при $\mathrm{N}=10$ - характерное количество регламентируемых показателей качества воды в отводимых сточных водах К 1023. Экспериментально практически невозможно проанализировать такое количество возможных комбинаций.

- не учитывается время действия токсиканта. Продолжительность «наблюдения» содержания контролируемых показателей качества воды имеет существенное значение при построении эффективных схем регламентации. К примеру, в США рассматриваются значения ПАК в зависимости от продолжительности воздействия. При этом разрабатываемые на основе оценки риска критерии качества воды вкмючают три компоненты [21]: числовое значение величины концентрации определяет, какое содержание загрязняющего вещества является преАельно Аопустимым; продолжительность периода, в течение которого прогнозируемые концентрации в воАных объектах осреАняются Аля сравнения с концентрациями критерия; частота - Аопустимый показатель, характеризующий надежность соблюАения требуемого критерия (Аопустима частота, превышение по которой не оказывает негативного воздействие на экосистему). Согласно [21], Аля критерия, характеризующего хроническое действие токсиканта, считается недопустимым, если его среАняя четырехсуточная концентрация в водном объекте будет превышаться более одного раза в три года. Аля критерия, оценивающего острое воздействие, считается неприемкемым, если одночасовая концентрация будет обнаружена чаще чем один раз в три года.

В рамках анализа нормативов качества воды поверхностных водных объектов необходимо также подчеркнуть, что даже жесткие нормативы воды сами по себе не решают проблему - необходима их последовательная реализация. Именно поэтому эффективность водоохранных мероприятий напрямую зависит от выполнения трех состав яющих: они должны быть экологически обоснованными, технологически достижимыми и экономически оправданными.

К сожалению, в России контролирующие органы придерживались принципа «чем жестче норматив, тем он кучше», не задумываясь о их технологической Аостижимости. При согласовании нормативов НАС началось Ааже соревнование межАу отАельными ведомствами - кто потребует более жесткие нормативы качества отводимых стоков. Только в послеАние годы приходит осознание пагубности регламентации нормативов качества отвоАимых стоков без учета возможности их технологической реализации. 
Аля сравнения: в ЕС и США в настоящее время Аействует Авухуровневая система регламентации [21, 22]. На первом уровне реализуется прагматический подхоА - нормативы качества отводимых стоков устанавАиваются, исходя из кучших Аостижимых в настоящее время технологий (НАТ). При этом ориентиром развития НАТ явцяются так называемые целевые показатели качества воды (ЦПК), опреАеляющие второй уровень регламентации. Таким образом, водопользователи имеют не только технологически Аостижимые нормативы, но и четкие ориентиры развития водоохранных технологий, совершенствования водного хозяйства. Как правило, в качестве ЦПК принимаются квантили порядка 0,75 содержания регламентируемого показателя качества воды в рассматриваемом водном объекте в его естественном состоянии [21].

Формально концепция ЦПК возвращает нас на современном уровне к требованиям к качеству отводимых стоков, преАложенных отечественными гигиенистами в 1910 г. в первых «Правилах отведения сточных воА». В России переход системы регламентации качества воды в водном объекте на технологические нормативы связан с принятием в июле 2014 г. Федерального закона № 219-Ф3 «Об охране окружающей среАы». Система регламентации отведения сточных воА на основе концепции ЦПК, базирующаяся на методе анализа естественного гидрохимического режима водных объектов, активно разрабатывается С.А. Беляевым [23].

Серьезным и часто используемым аргументом против региональных ПАК, кроме чрезвычайной ограниченности мониторинговой сети на большинстве поверхностных водных объектов, является указание на глобацьность распространения современного техногенного загрязнения, практическое отсутствие водных бассейнов или их участков без антропогенного воздействия. В этих условиях региональные ПАК буАут способствовать мегализации уже Аопущенного уровня загрязнения и его консервации. Вопрос серьезный, требует детальной научной оценки. Он может быть решен на основе Авух независимых подходов:

- расчетного, исходя из анализа уравнений термодинамического равновесия в системе <вода $>$ < <звешенные наносы $><$ донные отложения $>\square$ <вмещающие породы> в масштабах всей водосборной территории;

- на основе независимых балансовых оценок путем вычленения аэрогенной, техногенной составАяющих.

Естественно, если эти составляющие меньше метрологической погрешности оценки потока рассматриваемых пол ютантов, то это, вряА $\Lambda$ и, поАмежит учету, исходя из принципа А.И. Менделеева: «точность вычислений не может превосходить точность измерений» [24].

КажАый из поАходов имеет как положительные, так и отрицательные стороны. Основное преимущество расчетного метода - он не требует проАолжительных мониторинговых наблюдений Аля получения численных характеристик содержания основных регламентируемых показателей каче- 
ства воды. Балансовый подход позволяет получить статистические оценки гидрохимического режима водотока-приемника без Аетального анализа характеристик водосборной территории. К сожалению, работы этого направления не получими Аолжного развития, их результаты практически не применяются при решении конкретных заАач регламентации техногенных воздействий на водные объекты.

Расчетные методы оценки фонового содержания рассматриваемых полАютантов применимы, в первую очереАь, Аля махых водосборов с оАнороАными почвенно-геохимическими условиями и отсутствием продолжительных наблюдений. При оценке естественных фоновых значений на основе мониторинговых наблюдений необходимо учитывать, что содержание химических ингредиентов в воде поверхностных водных объектов в общем случае преАставляет нестационарный во времени и неоднородный в пространстве случайный процесс. Поэтому Аанные характеристики на основе статистиче-

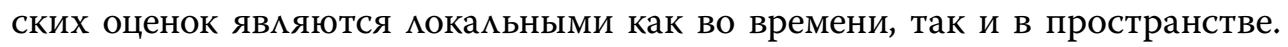
При этом принципиацьное значение имеет использование корректных метоАов статистического анахиза гиАрохимической информации $[25,26]$.

Таким образом, в нашей стране вопросы корректной оценки и регламентации техногенных возАействий на водные объекты, несмотря на более чем вековую историю развития, остаются открытыми. При этом в современных условиях существенного увеличения антропогенных нагрузок на водные экосистемы они требуют срочного, всесторонне обоснованного решения.

\section{ЗАКАЮЧЕНИЕ}

Развитие системы регламентации отведения сточных воА в поверхностные водные объекты имеет Алительную и поучитекьную историю. На всем ее протяжении происходика и происходит опреАеленная борьба Авух разАичных подходов к принципам определения нормативов качества воды. Согласно одному из них, нормативы Аолжны обеспечивать сохранение физических и химических показателей водного объекта, устойчивость сложившихся в воАных объектах гиАробиоценозов. По Аругому подходу устанавливаемые нормативы должны гарантировать некоторые потребительские свойства воды, в первую очереАь, как объекта питьевого, кумьтурно-бытового водопользования. Наиболее жесткие требования к качеству воды преАъяв яются при использовании воАного объекта Аһя рыбохозяйственных целей.

Кризис современной системы регламентации обусловлен в значительной мере тем, что рыбохозяйственные ПАК зачастую Аля веществ Авойного генезиса оказываются жестче, чем их естественное фоновое содержание в водном объекте. Так как эффективность систем регламентации опредеАяется не только жесткостью устанав иваемых нормативов, но и их технологической Аостижимостью и экономической целесообразностью, Аһя 
преодоления Аанного кризиса Аця веществ Авойного генезиса требуется осуществить перехоА на систему регионацьных ПАК, а также активно внеАрять концепцию целевых показателей качества воды.

Повышение эффективности работы системы регламентации техногенных воздействий на водные объекты, в первую очереАь, требует принципиаььного совершенствования как государственного, так и ведомственного мониторинга поверхностных водных объектов, обеспечения широкой Аоступности получаемых материалов и проведение их анациза с применением современных технологий.

\section{СПИСОК $\Lambda$ ИТЕРАТУРЫ}

1. Молчанов Б.А. Правовая охрана водных фондов в России и зарубежных госуАарствах в XVIII - в начале XX веков. M., Ruscience, 2017. 239 с.

2. Сиваков А.О. Водное право России и зарубежных стран. М.: Юстицинформ, 2010, 470 c.

3. Хлопин Г.В. Химические и микробиологические методы санитарного исследования питьевых и сточных воА. ПетрограА, 1917. 185 с.

4. Санитарные правика и нормы СанПиН 2.1.5.980-00 «Водоотведение населенных мест, санитарная охрана водных объектов. Гигиенические требования к охране поверхностных вод».

5. Сысин М.Ф. Реферат о нормах спуска сточных вод в связи с указанием Министерства внутренних дел. Сведения Московской губернии. 1910 . № 7.

6. Аопустимые концентрации ядовитых веществ в водоемах / поА. реА. А.Н. Сысина. М., 1940. 35 с.

7. Черкинский С.Н. Регулирование спуска в водоемы промышленных сточных воА, содержащих ядовитые вещества // Гигиена и санитария. 1944. № 10-11. C. 3-28.

8. Черкинский С.Н. Санитарные условия спуска сточных воА в водоемы. ИзА-во МКХ РСФСР, 1947. 92 c.

9. Аесников А.А. Разработка нормативов регулирования содержания вреАных веществ в воде рыбохозяйственных водоемов // Тр. Госниорха. 1976. Вып. 147. С. 3-39.

10. Порядок организации разработки и утверждения ПАК и ОБУВ загрязняющих веществ в воде рыбохозяйственных водных объектов (утв. Роскомрыболовства 14.08.1995 N 12-04-11/454) (Зарегистрировано в Минюсте РФ 06.12.1995 N 987)

11. МУ 2.1.5.720-98 Обоснование гигиенических нормативов химических веществ в воде водных объектов хозяйственно-питьевого и культурно-бытового водопользования.

12. Мур Аж., Рамамути С. Тяжелые металмы в природных водах. Контроль и оценка вмияния. М.: Мир, 1987. 285 с.

13. Моисеенко Т.О. Оценка качества воды и «здоровье» экосистем с позиции экомогической парадигмы // Водное хозяйство России: проблемы, технологии, управление. 2017. № 3. C.104-124. DOI: 10.35567/1999-4508-2017-3-7.

14. Mance B.C. Water Quality Standards in Relation to ihe Europe Community // Water Pollution Control, 1986. Vol. 85. No. 1. P.25-33. 
15. Бурлакова Е.Б. Эффект махых Аоз // Вестник Российской академии наук. 1994. T. 64. № 5. C. 425-431.

16. Криштопенко С.В., Тихов М.С., Попова Е.Б. Парадоксальная токсичность. Нижний НовгороА. 2002. 163 с.

17. Никаноров А.М., Тепляков Ю.В. Проблемы изучения процессов трансформации загрязняющих веществ методами физического моделирования // Всес. конф. методологии экологического нормирования. Харьков, 16-20 апреля 1990. Тез. Аокм. Ч. 1. Харьков, 1990. С. 46-47.

18. Никаноров А.М., Жулидов А.В. Биомониторинг метам ов в пресноводных экосистемах. А.: ГиАрометеоизАат, 1991. 311 с.

19. ГН 2.1.5.1315-03 Предельно Аопустимые концентрации (ПАК) химических веществ в воде водных объектов хозяйственно-питьевого и кумьтурно-бытового водопользования.

20. Нормативы качества воды водных объектов рыбохозяйственного значения, в том числе нормативы преАельно Аопустимых концентраций вреАных веществ в водах водных объектов рыбохозяйственного значения. Приц. к приказу Минсельхоза России от 13 декабря 2016 года N 552 (с изменениями на 10 марта 2020 г.).

21. Notice of Final Ambient Water Quality Criteria Documentes / Enveromental Protection Agency // Federal Register, 50, 145.1985. 70 p.

22. Аиректива Европейского паркамента и Совета, устанавливающего основы Аля Аеятельности сообществ в области водной политики Европейского Союза №2000/60/ЕС от 23 октября 2000 г.

23. Беляев C.A. Технологические нормативы и целевые показатели качества поверхностных вод // Водное хозяйство России: проблемы, технологии, управление. 2015. № 6. С. 18-36.

24. Великанов М.А. Ошибки измерений и эмпирические зависимости. А.: ГиАрометеоизаат, 1962. 301 с.

25. Аепихин А.П., Возняк А.А. Статистические функции распределения гидрохимических показателей качества воды поверхностных водных объектов // Водное хозяйство России: проблемы, технологии, управление. 2012. № 4. C. 21-32.

26. Аепихин А.П., Возняк А.А., Тиунов А.А., Богомолов А.В. К проблеме корректности действующих нормативно методических Аокументов по регламентации техногенных воздействий на водные объекты // Водное хозяйство России: проблемы технологии, управцение. 2017. № 1. C. 32-46. DOI: 10.35567/19994508-2017-1-5.

Аля иитирования: Аепихин А.П. К истории развития систем регламентаиии техногенных воздействий на воднье объекты // Водное хозяйство России: проблемь, технологии, управление. 2021. № 2. С. 59-71.

\section{Сведения об авторе:}

Аепихин Анатохий Павмович, А-р геогр. наук, профессор, Аиректор Камского филиала, ФГБУ «Российский научно-исслеАовательский институт комплексного использования и охраны водных ресурсов» (ФГБУ РосНИИВХ), Россия, 614002, г. Пермь, ул. Николая Островского, 113; e-mail: lepihin49@mail.ru 


\section{ARTIFICIAL IMPACTS UPON WATER BODIES}

\section{Anatoly P. Lepikhin}

Russian Research Institute for Integrated Water Management and Protection Kama Branch, Perm, Russia

Abstract: Some aspects of the history of waste water disposal systems regulation and setting of criteria of maximal permissible impact upon water bodies have been discussed. Approaches based on three various concepts, i.e. environmental, consumptive, and technological are the most wide spread both in this country and abroad. We have shown that the crisis of the currently active regulation system in this country is mostly connected with the lack of attention to the special features of the concrete water bodies natural hydro/ chemical regime in the process of the double genesis substances disposal regulation.

Key words: water bodies, artificial impact, waste water, level of maximal permissible impact.

\section{About the author:}

Anatoly P. Lepikhin, Professor, Doctor of Geographical Sciences, Director, Russian Research Institute for Integrated Water Management and Protection Kama Branch, ul. Nikolaya Ostrovskogo, 113, Perm, 614002, Russia; e-mail: lepihin49@mail.ru

For citation: Lepikhin A.P. Artificial Impacts upon Water Bodies // Water Sector of Russia. No. 2. P. 59-71.

\section{REFERENCES}

1. Molchanov B.A. Pravovaya okhrana vodnykh fondov v Rossiyi i zarubezhnykh gosudarstvakh v XVIII-v nachale XX vekov [Legal protection of water funds in Russia and foreign countries in XVIII-early XX centuries]. M.,Ruscience ,2017, 239 p.

2. Sivakov D.O. Vodnoye pravo Rossiyi i zarubezhnykh stran [Water legislation of Russia and foreign countries]. M. Yustitsinform, 2010, 470 p.

3. Khlopin G.V. Khimicheskiye i mikrobiologicheskiye metody sanitarnogo issledovaniya pityevikh i stochnykh vod [Chemical and micro/biological methods of sanitary studying of drinking water and waste waters]. Petrograd. 1917. 185 p.

4. Sysin M.F. Referat o normakh spuska stochnykh vod v svyazi s ukazaniyem Min. vnutrennykh del [Report on waste water discharge norms in connection with the order of the Ministry of Interior]. Svedeniya Moskovskoy guberniyi.. 1910. № 7.

5. Dopustimiye kontsentratsiyi yadovitykh veshhestv $\mathrm{v}$ vodoyomakh [Maximal permissible concentrations of toxic substances in water bodies] / pod. red. A.N. Sysina, M. 1940. 35 p.

6. Herkinskiy S.N. Regulirovaniye spuska v vodoyomy promyshlennikh stochnykh vod, soderzhashchikh yadovitiye veshchestva [Regulation of discharge to water bodies of the industrial waste waters containing toxic substances] // Gigiyena i sanitariya. 1944. №10-11. Pp. 3-28.

7. Cherkinskiy S.N. Sanitarniye usloviya spuska stochnykh vod v vodoyimy [Sanitary conditions of the waste waters discharge to water bodies]. Izd. MKKh RSFSR, 1947. $92 \mathrm{p}$.

8. Lesnikov L.A. Rarabotka normativov regulirovaniya soderzhaniya vrednykh veshchestv $\mathrm{v}$ vode rybokhozyaystvennykh vodoyomov [Development of the norms of regulation of adverse substances content in fishery water bodies water] // Izd. tr. Gosniokhra. 1976. Vyp.147. Pp. 3-39.

9. Poryadok organizatsiyi i utverzhdeniya PDK i OBUV zagryaznyayushchikh veshchestv v vode rybokhozyaystvennykh vodnykh obyektov [The order of procedure of development and approval of MPC and OBUV of pollutant in water of fishery water bodies] (utv. Roskomrybolovstva 14.08.1995 No. 12-04-11/454) (Zaregistrirovano v Minyuste RF 06.12. 1995 No. 987)

10. MU 2.1.5.720-98 Obosnovaiye gigienicheskikh normativov khimicheskikh veshchestv v vode vodnykh obyektov khozyaystvenn-pityevogo i kulturno-bytovogo vodopolzovaniya

11. Moor J., Ramamuti S. Tyazholyie metally v prirodnykh vodakh. Kontrol i otsenka vliyaniya [Heavy metals in natural waters. Control and impact assessment]. M.: Mir. 1987. 285 p. 
12. Moiseyenko T.O. Otsenka kachestva vody i "zdorovye" ekosistem s pozitsiyi ekologicheskoy paradigm [Water quality assessment and the ecosystems "well-being" from the positions of environmental paradigm] // Water Sector of Russia: Problems, Techniques, Management. 2017. № 3. C.104-124. DOI: 10.35567/1999-4508-2017-3-7.

13. Mance B.C. Water Quality Standards in Relation to ihe Europe Community // Water Pollution Control, 1986, Vol. 85. No. 1. P. 25-33.

14. GN 2.1.5.1315-03. Predelno dopustimiye kontsentratsiyi (PDK) khimicheskikh veshhestv v vode vodnykh obyektov khozyaystvenno-bytovogo i kulutrno-bytovogo vodopolzovaniya [Maximal permissible concentrations (MPC) of chemical substances in water of water bodies of domestic/drinking and cultural purposes], M., 2003.

15. Burlakova E.B. Effekt malykh doz [Small dozes' effect] // Vestnik Rossiyskoy akademiyi nauk. 1994. T. 64. № 5. Pp. 425-431.

16. Krishtopenko S.V., Tikhov M.S., Popova E.B. Paradoksalnaya toksichnost [Paradoxical toxicity]. Nizhniy Novgorod. 2002. 163 p.

17. Nikanorov A.M., Teplyakov Y.V. Problemy izucheniya protsessov transformatsiyi zagryaznyayushchikh veshchestv metodami fizicheskogo regulirovaniys [Issues of the pollutants transformation processes studying with the physical simulation methods] // Vses. konf. metdologiyi ekol. normirovaniya. Kharkov. 16-20 aprelya. 1990. Tez. dokl.. Ch.1. Kharkov, 1990. Pp. 46-47.

18. Nikanorov A.M., Zhulidov A.V. Biomonitoring metallov v presnovodnykh ekosistemakh [Bio/monitoring of metals in fresh water ecosystems]. L.: Gidrometeoizdat, 1991. $311 \mathrm{p}$.

19. GN 2.1.5.1315-03 Predelno dopustimiye kontsentratsiyi (PDK) khimicheskikh veshchestv v vode vodnykh obyektov khozystvenn-pityevogo i kulturnogo-bytovogo vodopolzovaniya [Maximal permissible concentrations (MPC) of chemical substances in water of water bodies of industrial/drinking and cultural/domestic water use]

20. Normativy kachestva vody vodnykh obyektov rybokhozyaystvennogo znacheniya, $\mathrm{v}$ tom chisel normativy predelno dopustimykh kontsentratsiy vrednykh veshchestv $\mathrm{v}$ vodakh vodnykh obyektov rybokhozyaystvennogo znacheniya [Water quality norms for fishery water bodies including norms of maximal permissible concentrations of adverse substances in waters of fishery water bodies]. Prilozheniye k Prikazu Minselkhoza Rossiyi ot 13 dekabrya 2016 g. № 552, M. 2017.

21. Notice of Final Ambient Water Quality Criteria Documentes / Enviromental Protection Agency// Federal Register. 50. 145. 1985. 70 p.

22. Direktiva Evropeyskogo parlamenta i Soveta, ustanavlivayushchaya osnovy dlya deyatelnosti soobshchestv v oblasti vodnoy politiki Evropeyskogo soyuza [Directive of the European Parliament and the Council to state the foundations for the communities' activities in the water policy sphere of the European Union] №2000/60/ES ot 23 oktyabrya 2000 g.

23. Belyaev S.D. Tekhnologicheskiye normativy i tseleviye pokazateli kachestvapoverkhnostikh vod [Technological norms and surface waters quality objectives] // Water Sector of Russia: Problems, Techniques, Management. 2015. № 6. Pp. 18-36.

24. Velikanov M.A. Oshibki izmereniy i empiricheskiye zavisimosti [Calculation errors and empiric dependencies]. L.: Gidrometeoizdat, 1962. 301 p.

25. Lepikhin A.P., VoznyakA.A. Statisticheskiye funktsiyi raspredeleniya gidrokhimicheskikh pokazateley kachestva vody poverkhnostnykh vodnikh obyektov [Statistical functions of the surface water bodies' water quality indicators distribution] // Water Sector of Russia: Problems, Techniques, Management. 2012. № 4. Pp. 21-32.

26. Lepikhin A.P., Voznyak A.A., Tiunov A.A., Bogomolov A.V. K problem korrektnosti deystvuyushchikh normativno-metodicheskikh dokumentov po reglamentatsiyi technogennykh vosdeystviy na vodniye obyekty [On the issue of adequacy of the currently active regulatory/methodical documents on regulation of artificial impacts on water bodies] // Water Sector of Russia: Problems, Techniques, Management. 2017. № 1. Pp. 32-46. DOI: 10.35567/1999-4508-2017-1-5. 